\title{
Study of serum glucose and cholesterol level in schizophrenic patient's before and after treatment of olanzapine, risperidone and haloperidol
}

\author{
Ajay Kumar Halwai ${ }^{1}$, Vinod Koshley ${ }^{2, *}$, Rajesh Hishikar ${ }^{3}$, Basant Maheshwari ${ }^{4}$, Usha Joshi ${ }^{5}$ \\ ${ }^{\mathbf{1 , 2}}$ Assitant Professor, ${ }^{3}$ Professor, ${ }^{4,5}$ Associate Professor, ${ }^{\mathbf{1 , 3}, 4,5}$ Dept. of Pharmacology, ${ }^{2}$ Dept. of Dermatology (Skin \& V.D), \\ Pt. Jawahar Lal Nehru Memorial Medical College, Raipur, Chhattisgarh, India
}

*Corresponding Author:

Email: drvinodkoshley@gmail.com

\begin{abstract}
Objectives: To evaluate the potential association between antipsychotics (Olanzapine, Risperidone and Haloperidol), serum glucose level and serum cholesterol level in schizophrenic patients.

Introduction: Schizophrenia is quite prevalent and has high rate of chronicity and morbidity. Newer atypical antipsychotic drugs were developed in response to limitations such as lack of efficacy and side effects associated with older (conventional) agents. However, significant hyperglycemia, dyslipidemia and weight gain have been reported with the use of newer atypical antipsychotics.

Materials and Methods: This was an observational prospective study. Total 75 schizophrenic patients were divided in three groups according to treatment allocated (group I- olanzapine, group II- risperidone, group III haloperidol) comprising of 25 patients in each group. Blood sample was collected when patient came to hospital for the first time before starting the treatment and 6 weeks after treatment, then again 6 months after treatment, fasting serum glucose and cholesterol levels were estimated by enzymatic procedure. Simultaneously body weight was also measured.

Results: In this study majority of patients were male-73.33\% with mean age of 30.76 years. There were significant increase in serum glucose levels and serum cholesterol level, after 6 weeks and 6 months of treatment $(t=3.11 p<0.01, t=4.32 p<0.001$ respectively) and $(\mathrm{t}=1.98 \mathrm{p}<0.05$.

$\mathrm{t}=3.65 \mathrm{p}<0.001$ respectively), In Group I (Olanzapine treated patients). Body weight was also significantly increased ( $\mathrm{t}=3.11$, $\mathrm{p}<0.001)$.There were no significant increase in serum glucose levels, serum cholesterol levels and body weights in Group II (Risperidone treated group) and Group III (Haloperidol treated group).
\end{abstract}

Conclusion: Olanzapine was associated with increased risk of glucose intolerance, dyslipidemia and weight gain.

Keywords: Antipsychotics, Schizophrenia, Cholesterol, Diabetes, Weight gain.

\section{Introduction}

Schizophrenia is a heterogeneous syndrome characterized by perturbations of language, perception, thinking, social activity, affect and volition. Patient may present with positive symptoms (such as conceptual disorganization, delusions and hallucinations) or negative symptoms (loss of function, anhedonia, decreased emotional expression, impaired concentration, and diminished social Engagement). Schizophrenia is quite prevalent and has high rate of chronicity and morbidity. Chlorpromazine and other typical antipsychotics such as Haloperidol, Fluphenazine, Trifluphenazine, hioridazine, Molindone, and a Loxapine were introduced to treat schizophrenia. These drugs are dopamine D2 receptor antagonist and effective in treating the positive symptoms of schizophrenia, they are usually less effective against the negative symptoms. Furthermore, their antagonist activity at dopamine D2 receptor is associated with significant side effects including EPS (extrapyramidal symptoms), tardive dyskinesia and hyperprolactinemia. Conventional antipsychotic drugs also block other receptor sites to varying degrees (e.g. Histaminic, Adrenergic, and Muscarinic). ${ }^{1}$ Action of drug on these receptors results in adverse effects; such a high incidence of side effects may affect compliance with these medications.
Newer atypical antipsychotic drugs ${ }^{2}$-were developed in response to limitations such as lack of efficacy and side effects associated with older (conventional) agents these are Clozapine, Olanzapine, Risperidone, Quetiapine, Ziprasidone and Aripiprazole. Unlike the older, conventional antipsychotic agents, atypical antipsychotic drugs not only improve the positive symptoms of schizophrenia, but may also have greater efficacy in improving the negative symptoms. Also, most atypical agents appear to have a lower propensity to cause EPS and serum prolactin level elevations. However, atypical antipsychotics were associated with other side effects like substantial weight gain, hyperglycemia, cholesterol level elevation, and QT interval prolongation. ${ }^{3}$

Hyperglycemia in the context of treatment with atypical antipsychotic medications has been documented in several series of uncontrolled case reports, and Clozapine and Olanzapine have been implicated more frequently than Risperidone. ${ }^{4,5}$ Complicating this issue is the observation that the patients with schizophrenia are more likely to develop DM than the general population, regardless of antipsychotic use. $^{6}$ Significant elevations in Triglyceride \& Cholesterol levels have also been reported in association with atypical antipsychotic treatment. ${ }^{7-9}$ These adverse effects associated with 
second-generation antipsychotics are also part of the metabolic syndrome, which has been associated with higher morbidity and mortality from cardiovascular disorders than its individual component.

Therefore, the objective of this study was to evaluate the potential association between antipsychotics (Olanzapine, Risperidone and Haloperidol), serum glucose level and serum cholesterol level by Prospective trial in 75 patients with schizophrenia. Effect on weight gain was also evaluated.

\section{Materials and Methods}

This was a hospital based observational prospective study. Total 75 schizophrenic patients from psychiatry OPD/Ward, during September 2008 to November 2009 were included according to inclusion and exclusion criteria. The diagnosis of these patients were reviewed and confirmed by two consultant Psychiatrist according to ICD-10 criteria. These Schizophrenic patients were divided into three groups according to treatment allocated (Group-I Olanzapine, Group-II Risperidone, Group-III Haloperidol) comprising of 25 patients in each group. These patients were followed up for 6 month. Each patient selected for this study was given a self-designed pro-forma for general information and socioeconomic status. All patient of this group were matched for age, sex, education and socio-economic status. Written informed consent were obtained from each patient. Study was conducted in Department of Pharmacology, Department of Biochemistry, Department of Psychiatry, in Pt. J.N.M Medical College \& associated Dr. B.R.A.M. Hospital Raipur (C.G.) the selection criteria for inclusion of the patient in the study were;

\section{Inclusion Criteria}

1. All the new \& old patients (who are not on any treatment) of either sex fulfilling the diagnostic criteria as per ICD -10 for schizophrenia ${ }^{10}$ or schizo-affective disorder were taken in the study.

2. Age group 18-50 years.

\section{Exclusion Criteria:-}

1. Psychotic patient who are taking any antipsychotic drug treatment in the last one month.

2. If the subject is women who is pregnant or breast feeding or at risk of pregnancy during therapy.

3. Chronic physical illness, Organic brain syndrome, Substance dependence.

4. Any other co-morbid medical illness (Diabetes, Hypertension).

5. Patient taking Diabetogenic drugs (Thiazide, Diuretic and Steroids).

6. If the patients suffering from hepatic, renal, metabolic or neurological disorder (Parkinsonism or movement disorder).

7. Uncooperative patients.
8. Age group below 18 years \& above 50 years

9. Patient with family history of diabetes.

\section{Drug Doses and Schedule}

Patients of Group I were given Olanzapine in dose of 5-20 mg once a day schedule, patients of Group II were given Risperidone in dose of 2-10 mg once a day schedule, patients of Group III were given Haloperidol in dose of 10-40 mg once a day schedule. Doses were adjusted according to response and undesirable side effects.

\section{Procedure \& Schedule}

Blood sample were collected at the starting of the treatment and 6 weeks after treatment and 6 months after treatment. $3 \mathrm{ml}$ i.e. blood is taken in plane vial by disposable syringe. These blood samples were allowed to clot then serum was separated from clotted blood sample. Serum glucose level and serum cholesterol level were estimated by enzymatic procedure. Body weight were also measured by weighing machine.

\section{Statistics}

Sampling Method: Quota sampling

Analysis of result

Arithmetic mean and standard deviation were calculated. Paired t-test were conducted and p-value were obtained.

\section{Results}

Total 75 patient were included in this study. Age wise distribution of patients in present study is shown in Fig. 2. Out of 75 patients, $37.33 \%$ were in the age group of $18-26$ years, $34.67 \%$ cases in the age group of $27-35$ years, $24 \%$ patients in the age group of 36-44 years and $4 \%$ patients in the $45-52$ years. Overall mean age of present study was 30.76 years. Sex wise distribution of patients in present study is as shown in Fig. 3. Majority of the patients in this study were male $(73.33 \%)$

Change in glucose level after 6 week and 6 month of treatment is shown in table $1 \& 2$ respectively. significant change in fasting serum glucose after 6 week and 6 month of treatment in olanzapine treated group was observed $(\mathrm{t}=3.11, \mathrm{p}=<0.01, \mathrm{t}=4.32, \mathrm{p}=<0.001$ respectively). No significant change in fasting serum glucose levels is observed in Risperidone and Haloperidol treated group.

Change in serum cholesterol level are as shown in Table 3 \& 4, It was observed that there was a statistically significant increase in fasting cholesterol levels, after 6 week and 6 months interval in Olanzapine treated group $[\mathrm{t}=1.98 \mathrm{p}<0.05, \mathrm{t}=3.65$ $\mathrm{p}<0.001]$ respectively. No statistically significant changes in fasting serum cholesterol level is observed with Risperidone treated group and Haloperidol treated group.

(Table 5) \& (Table 6) is showing change in body weight 6 week and 6 month after treatment respectively 
.no significant change in Body weight in Olanzapine, Risperidone and Haloperidol treated group after 6 weeks of treatment was observed. There was significant change in body weight in Olanzapine treated group after six months of treatment $(\mathrm{t}=3.11, \mathrm{p}<0.01)$. No significant change in body weight in Risperidone and
Haloperidol treated group. Mean increase in body weight in Olanzapine teated group, Risperidone teated group and in Haloperidol teated group after 6 months was $6.61 \pm 3.33 \mathrm{~kg}, 2.53 \pm 1.95 \mathrm{~kg}$ and $1.75 \pm 0.47 \mathrm{~kg}$ respectively.

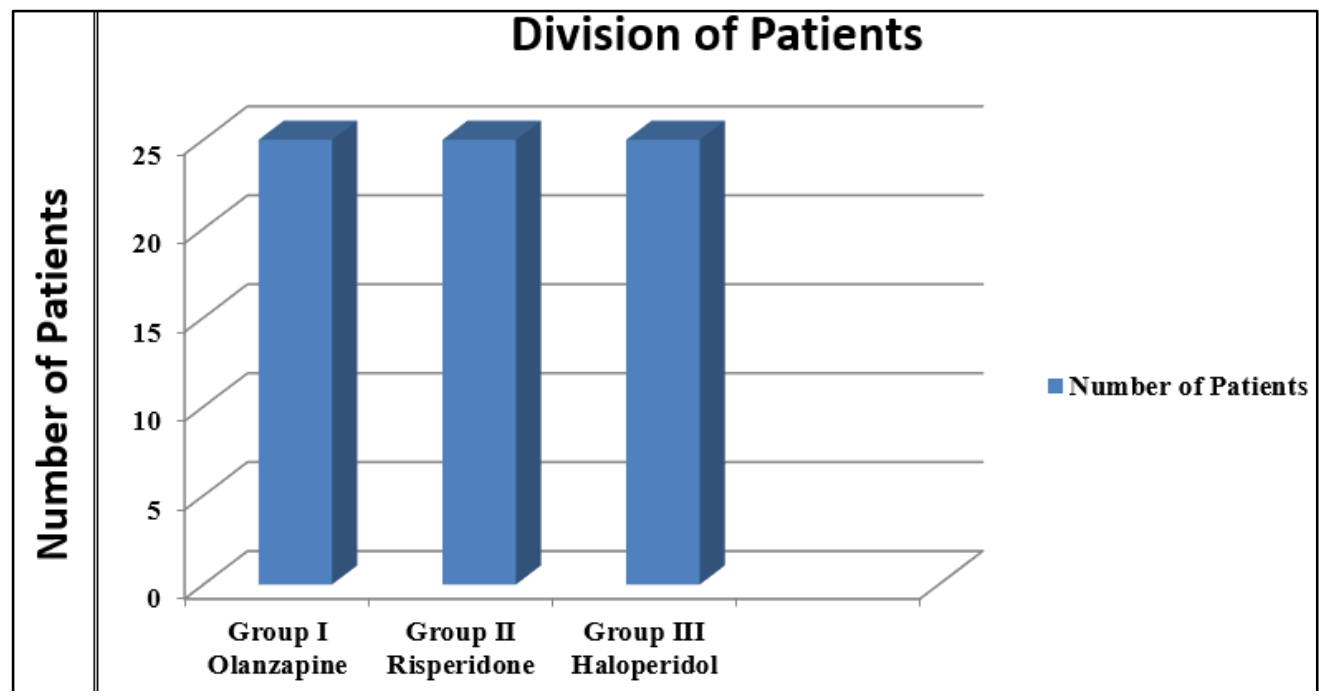

Fig. 1: Division of patient

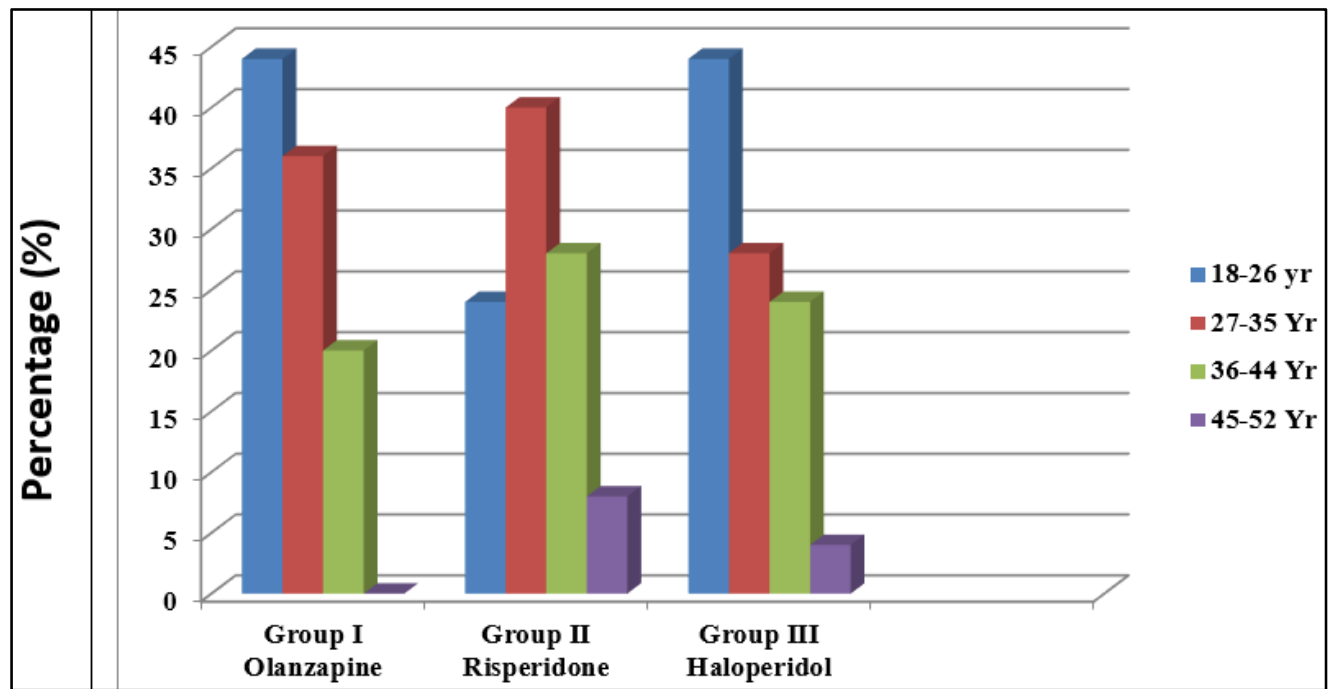

Fig. 2: Age wise distribution of patients 


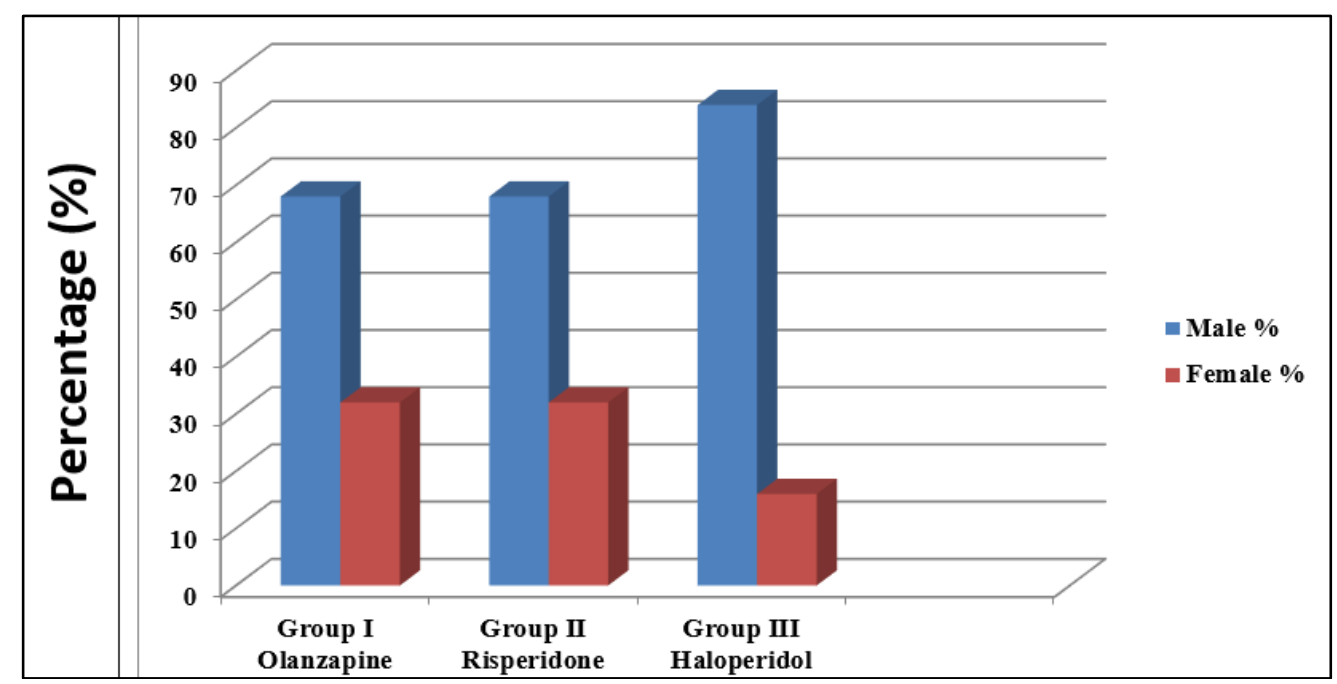

Fig. 3: Sex wise distribution of patients

Table 1: Change in fasting serum glucose levels of 75 patients of schizophrenia after 6 weeks of treatment with three antipsychotic medications

\begin{tabular}{|c|c|c|c|c|c|c|c|c|c|c|}
\hline \multirow[t]{3}{*}{ Medications } & \multirow{2}{*}{\multicolumn{2}{|c|}{$\begin{array}{c}\text { Base Line } \\
\text { Serum Glucose } \\
\text { Level (mg/dl) }\end{array}$}} & \multicolumn{4}{|c|}{6 weeks } & \multirow{2}{*}{\multicolumn{2}{|c|}{$\begin{array}{c}\text { Change from } \\
\text { Baseline }\end{array}$}} & & \\
\hline & & & & $\begin{array}{r}\mathbf{m G} \\
(\mathrm{n}\end{array}$ & $\begin{array}{l}\text { ose Le } \\
\text { li) }\end{array}$ & & & & \multicolumn{2}{|c|}{ Analysis } \\
\hline & No & Mean & SD & No & Mean & SD & Mean & SD & $\mathrm{t}$ & $\mathrm{p}$ \\
\hline Olanzapine & 25 & 86.64 & 8.82 & 25 & 94.58 & 8.9 & 7.08 & 9.32 & 3.11 & $<0.01$ \\
\hline Risperidone & 25 & 85.8 & 12.5 & 25 & 91.33 & 13 & 5.12 & 17.72 & 1.53 & $\mathrm{~ns}$ \\
\hline Haloperidol & 25 & 81.92 & 9.17 & 25 & 84.44 & 7.58 & 3.56 & 10.97 & 1.07 & ns \\
\hline
\end{tabular}

$\mathrm{No}=$ Number of patients, $\mathrm{SD}=$ standard deviation, $\mathrm{ns}=$ non significance.

Table 2: Change in fasting serum glucose levels of 75 patients of schizophrenia after 6 months of treatment with three antipsychotic medications

\begin{tabular}{|l|c|c|c|c|c|c|c|c|c|c|}
\hline & \multicolumn{3}{|c|}{ Base Line } & \multicolumn{3}{c|}{ 6 months } & \multicolumn{2}{c|}{$\begin{array}{c}\text { Change from } \\
\text { baseline }\end{array}$} & \multicolumn{2}{c|}{ Analysis } \\
\hline & \multicolumn{3}{|c|}{$\begin{array}{c}\text { Serum Glucose Level } \\
\text { (mg/dl) }\end{array}$} & \multicolumn{2}{c|}{$\begin{array}{c}\text { Serum Glucose Level } \\
\text { (mg/dl) }\end{array}$} & \multicolumn{2}{|c|}{} \\
\hline Medication & No & Mean & SD & No & Mean & SD & Mean & SD & t & p \\
\hline Olanzapine & 25 & 86.64 & 8.82 & 25 & 101.1 & 14.3 & 14.08 & 12.76 & 4.32 & $<0.01$ \\
\hline Risperidone & 25 & 85.8 & 12.48 & 25 & 89.25 & 15.9 & 3.56 & 18.79 & 0.97 & $\mathrm{~ns}$ \\
\hline Haloperidol & 25 & 81.92 & 9.17 & 25 & 85.24 & 13.6 & 3.24 & 16.25 & 1.01 & $\mathrm{~ns}$ \\
\hline
\end{tabular}

$\mathrm{No}=$ Number of patients, $\mathrm{SD}=$ Standard deviations, $\mathrm{ns}=$ no significance.

Table 3: Change in fasting serum cholesterol levels of 75 patients of schizophrenia after 6 weeks of treatment with three antipsychotic medications

\begin{tabular}{|l|c|c|c|c|c|c|c|c|c|c|}
\hline & \multicolumn{3}{|c|}{ Base Line } & \multicolumn{3}{c|}{ 6 Weeks } & \multicolumn{2}{c|}{$\begin{array}{c}\text { Change from } \\
\text { baseline }\end{array}$} & \multicolumn{2}{c|}{ Analysis } \\
\hline & \multicolumn{3}{|c|}{$\begin{array}{c}\text { Serum Cholesterol Level } \\
\text { (mg/dl) }\end{array}$} & \multicolumn{3}{c|}{$\begin{array}{c}\text { Serum Cholesterol } \\
\text { Level (mg/dl) }\end{array}$} & & \\
\hline Medication & No & Mean & SD & No & Mean & SD & Mean & SD & $\mathrm{t}$ & $\mathrm{p}$ \\
\hline Olanzapine & 25 & 142.48 & 43.51 & 25 & 166.16 & 49.81 & 20.32 & 55.77 & 1.98 & $<0.05$ \\
\hline Risperidone & 25 & 132.12 & 35.57 & 25 & 134.04 & 37.97 & 3.68 & 44.54 & 0.84 & $\mathrm{~ns}$ \\
\hline Haloperidol & 25 & 138.96 & 20.61 & 25 & 143.64 & 25.84 & 4.68 & 32.67 & 0.86 & $\mathrm{~ns}$ \\
\hline
\end{tabular}

$\mathrm{No}=$ Number of patients, $\mathrm{SD}=$ Standard deviations, $\mathrm{ns}=$ no significance 
Table 4: Change in cholesterol levels of 75 patients of schizophrenia after 6 months of treatment with three antipsychotic medications

\begin{tabular}{|l|c|c|c|c|c|c|c|c|c|c|}
\hline & \multicolumn{3}{|c|}{ Base Line } & \multicolumn{3}{c|}{ 6 months } & \multicolumn{2}{c|}{$\begin{array}{c}\text { Change from } \\
\text { baseline }\end{array}$} & \multicolumn{2}{c|}{ Analysis } \\
\hline & \multicolumn{3}{|c|}{$\begin{array}{c}\text { Serum Cholesterol Level } \\
\text { (mg/dl) }\end{array}$} & \multicolumn{3}{c|}{$\begin{array}{c}\text { Serum Cholesterol } \\
\text { Level (mg/dl) }\end{array}$} & & & \\
\hline Medication & No & Mean & SD & No & Mean & SD & Mean & SD & t & p \\
\hline Olanzapine & 25 & 142.48 & 43.51 & 25 & 186.64 & 33.45 & 40.4 & 39.89 & 3.65 & $<0.001$ \\
\hline Risperidone & 25 & 132.12 & 35.57 & 25 & 140.68 & 36.35 & 9.2 & 43.9 & 0.11 & $\mathrm{~ns}$ \\
\hline Haloperidol & 25 & 138.96 & 20.61 & 25 & 145.92 & 30.79 & 7.04 & 40.38 & 0.93 & $\mathrm{~ns}$ \\
\hline
\end{tabular}

$\mathrm{No}=$ Number of patients, $\mathrm{SD}=$ Standard deviations, $\mathrm{ns}=$ no significance

Table 5: Change in body weight of 75 patients of schizophrenia after 6 weeks of treatment with three antipsychotic medications

\begin{tabular}{|l|c|c|c|c|c|c|c|c|c|c|}
\hline & \multicolumn{3}{|c|}{ Base Line } & \multicolumn{3}{c|}{ 6 Weeks } & \multicolumn{2}{c|}{$\begin{array}{c}\text { Change from } \\
\text { baseline }\end{array}$} & \multicolumn{2}{c|}{ Analysis } \\
\hline & \multicolumn{3}{|c|}{ Body Weight (Kg) } & \multicolumn{2}{c|}{ Body Weight (Kg) } & \multicolumn{2}{c|}{} \\
\hline Medication & No & Mean & SD & No & Mean & SD & Mean & SD & t & $\mathrm{p}$ \\
\hline Olanzapine & 25 & 60.78 & 7.39 & 25 & 61.94 & 7.37 & 1.14 & 0.73 & 0.56 & $\mathrm{~ns}$ \\
\hline Risperidone & 25 & 64.18 & 11.27 & 25 & 65.32 & 11.08 & 1.02 & 0.49 & 0.36 & $\mathrm{~ns}$ \\
\hline Haloperidol & 25 & 61.05 & 8.48 & 25 & 61.84 & 8.33 & 0.83 & 0.44 & 0.13 & $\mathrm{~ns}$ \\
\hline
\end{tabular}

$\mathrm{No}=$ Number of patients, $\mathrm{SD}=$ Standard deviations, $\mathrm{ns}=$ no significance

Table 6: Change in body weight of 75 patients of schizophrenia after 6 months of treatment with three antipsychotic medications

\begin{tabular}{|c|c|c|c|c|c|c|c|c|c|c|}
\hline & \multicolumn{3}{|c|}{ Base Line } & \multicolumn{3}{c|}{ 6 Months } & \multicolumn{2}{c|}{$\begin{array}{c}\text { Change from } \\
\text { baseline }\end{array}$} & \multicolumn{2}{c|}{ Analysis } \\
\hline & \multicolumn{3}{|c|}{ Body Weight (Kg) } & \multicolumn{3}{c|}{ Body Weight (Kg) } & \multicolumn{2}{c|}{} \\
\hline Medication & No & Mean & SD & No & Mean & SD & Mean & SD & t & $\mathrm{p}$ \\
\hline Olanzapine & 25 & 60.78 & 7.39 & 25 & 67.45 & 7.8 & 6.64 & 3.33 & 3.11 & $<0.01$ \\
\hline Risperidone & 25 & 64.18 & 11.27 & 25 & 66.51 & 11.07 & 2.53 & 1.95 & 0.77 & $\mathrm{~ns}$ \\
\hline Haloperidol & 25 & 61.05 & 8.48 & 25 & 62.8 & 8.28 & 1.75 & 0.47 & 0.31 & $\mathrm{~ns}$ \\
\hline
\end{tabular}

$\mathrm{No}=$ Number of patients, $\mathrm{SD}=$ Standard deviations, $\mathrm{ns}=$ no significance

\section{Discussion}

In a similar study done by Linden Mayer JP et al ${ }^{11}$ in 101 patients and observed that clozapine, haloperidol and olanzapine treatment were associated with significant increases from baseline in Mean glucose levels .No significant increase in glucose level was observed with risperidone treated patients. They also found that mean cholesterol levels were increased in patients treated with olanzapine and clozapine. Results of this study are consistent with the results of present study. In an another study done by Lambert et al ${ }^{12}$, found that exposure to olanzapine or clozapine is associated with a 34-41\% increase in the developing of type 2 diabetes and an increased risk of hyperlipidemia among people with schizophrenia. Fuller MA et al ${ }^{13}$ studied and found that olanzapine was associated with a $37 \%$ (HR 1.37) increased risk of development of diabetes compared with risperidone. Handerson DC et $\mathrm{al}^{14}$ studied and determined that both nonobese clozapine-and olanzapine-treated groups displayed.
Significant insulin resistance and impairment of glucose effectiveness compared with risperidonetreated subjects.

Winkel V R et $\mathrm{al}^{15}$ Studied and finally suggested that the incidence of new-onset glucose abnormalities, including diabetes, in the first 3 months after newly starting or switching atypical antipsychotic medication(olanzapine, clozapine, quetiapine) is high and may be markedly influenced by type of prescribed antipsychotic. Melkersson KI et $\mathrm{al}^{16}$ studied and concluded that Olanzapine

Treatment was associated with weight gain and elevated levels of insulin, leptin, and blood lipids as well as insulin resistance, with 3 patients diagnosed to have diabetes mellitus. Wirshing DA et $\mathrm{al}^{17}$ retrospectively assessed and found that the glucose levels and triglyceride level were increased from baseline for patients treated with clozapine and olanzapine compared with risperidone and typical antipsychotics treated patients.

The exact mechanism of antipsychotics-induced weight gain is not clear, but several hypothesis has been 
given. Initially, Histamine receptor blockage was considered causative factor for the conventional antipsychotic-induced weight gain ${ }^{18}$ and is supported by empirical data. Drugs with high affinity for histamine receptor, are also associated with high rates of weight gain like olanzapine. Ziprasidone and risperidone, have lower affinity for histamine receptors are associated with lower risk of weight gain.

Leptin is a hormone secreted by adipose tissue to have effects at receptors in the hypothalamus that result in the control of food intake. Deficits in leptin or leptin receptors result in overeating and obesity, indicating the importance of the hormone in body mass homoeostasis. A subsequent study found that leptin was increased in patients treated with clozapine and olanzapine but not patients treated with haloperidol. Patients continue to overeat despite high circulating leptin levels. An 8 weeks study found significant increase in body weight, serum leptin levels and percentage of body fat in patients treated with olanzapine but not in the drug free comparison group. ${ }^{19}$

Several mechanisms of glucose dysregulation have been proposed to explain this association. The medications most commonly associated with diabetes are also those that induce the greatest amount of weight gain. There are patients who develop diabetes; however, in the absence of weight gain, other causes must be sought. These drugs may disrupt hypothalamic regulation of glucose serum levels through hypothalamic dopamine antagonism. Additionally, elevated insulin levels have been found in $46 \%$ of clozapine-treated patients, compared with $21 \%$ of those receiving conventional Medicines and $71 \%$ of a small sample of olanzapine-treated patients, suggesting that insulin resistance is a possible mechanism. ${ }^{20}$

A role of prolactin in the dysregulation of glucose metabolism has also been suggested. Prolactin has been found to be elevated during treatment with antidopaminergic drug and this has been linked to lower insulin sensitivity, subsequently leading to insulin resistance. $^{21,22}$

Potent anticholinergic activity as contributing factor for glucose dysregulation is demonstrated by Johnson et al. ${ }^{23}$ In their study, they found that olanzapine and clozapine by blocking muscarinic M3 receptor activity inhibits cholinergic -induced insulin secretion in vitro. Drugs with low potency anticholinergic activity has no such effects for example Risperidone and ziprasidone.

The relative risk for development type-2 DM during antipsychotic treatment seems to match the potential to cause increase in weight gain by the different drugs. This hypothesis is contradicted by findings that a significant minority of patients may develop altered glucose metabolism independent of weight gain. ${ }^{24-26}$ These observations suggest the hypothesis that antipsychotic medications may have a direct effect on insulin secretion or sensitivity.
In another study done by Newcomer JW et al also suggest that weight gain may not explain all the observed metabolic adverse effects. They compared the effects of conventional and atypical antipsychotics on glucose regulation in chronically treated nondiabetic patients with schizophrenia and in untreated healthy control subjects. ${ }^{27}$ Patients who received olanzapine and clozapine had higher calculated insulin resistance, compared with those who received conventional agents ( $\mathrm{P}<0.05$ and $\mathrm{P}<0.08$, respectively), whereas those who received risperidone or typical antipsychotics did not differ from control subjects. Similar findings were reported by Henderson and colleagues, in their study. ${ }^{14}$

The mechanism causing hyperlipidemia are even less clear. The most likely one is weight gain. Dietary changes as well as glucose intolerance are also suggested to cause hyperlipidemia.

In present study it was observed that there was no correlation between weight gain and increase in serum glucose and cholesterol levels. We observed patients who did not gain weight while taking olanzapine, but who did develop increase in serum glucose and cholesterol levels, suggesting that mechanism other than obesity may be involved in hyperglycemia and hypercholesterolemia with olanzapine treatment. . Other potential risk factors which can influence the above parameter should be taken in consideration, such as; concomitant medications and dietary factors. Another potential risk factor is the lack of physical activity; patients are frequently less active because of the sedating quality of olanzapine. Exercise may be a protective factor for type $2 \mathrm{DM}$ and glucose intolerance.

Studies on this important topic are rather limited, especially over Indian population. This was the first study on this topic in the Chhattisgarh state. Though we tried our level best with the honest and exhaustive approach toward conducting this study, but since it is a hospital based, it has its limitation. Further controlled study on this topic should be conducted to evaluate the mechanism behind the metabolic adverse effects of antipsychotics.

\section{Conclusion}

On the basis of the data of present study it can be concluded that: Olanzapine treatment was associated with significant increase in serum glucose levels \& serum cholesterol levels. It was also associated with significant increase in body weight. No significant increase in serum glucose levels, serum cholesterol levels, and body weight was observed with Risperidone and Haloperidol treatment. For reduction of these serious adverse effects and its consequences, patients treated with antipsychotics should be subjected to appropriate baseline screening as well as ongoing monitoring. 


\section{Acknowledgement}

My sincere thanks -Department of Psyciatry, Dr

BRA Hospital, Raipur, C.G., Department of

Biochemistry, Pt. JNM Medical College, Raipur, C.G.

\section{References}

1. Sadock BJ, Sadock VA. Kaplon and sudock's synopsis of psychiatry: dopamine receptor antagonist-typical antipsychotic. 10th edition. Philadelphia: Lippinctt Williams \& Williams; 2007.1047-1048.

2. Janssen-Ortho. History of treatingschizophrenia.last updated on July 27, 2007.available from URL; http://www.invega.com/invega/about-history.

3. Dhar HL, Dave KP. Current Use of Atypical Antipsychotics in Resistant Schizophrenia. Available from URL:

phttp://www.bhj.org/journal/2004_4602_april/html/curre ntuseo f_151.html

4. Ai D, Roper TA, Riley JA. Diabetic ketoacidosis and clozapine. Postgrad Med J.1998; 74:493-494.

5. Lindenmayer JP, Nathan A, Smith RC. Hyperglycemias associated with the use of atypical anti- psychotics. J Clin Psychiatry, 2001;62(suppl 23):30-38

6. Dixon L, Weiden P, Delahanty J, Goldberg R, Postrado L, Lucksted A, Lehman A. Prevalence and correlates of diabetes in national schizophrenia samples. Schizophrenia Bull .2000;26:903-912.

7. Melkersson KI, Hulting AL, Brismar KE. Elevated levels of insulin, leptin, and blood lipids in olanzapine-treated patients with chronic schizophrenia and schizoaffective disorder. Am J Psychiatry. 2002; 159:255-262.

8. Meyer JM. A retrospective comparison of lipid, glucose, and weight changes at one year between olanzapine and risperidone treated inpatients, in Proceedings of the 39th Annual Meeting ofthe American College of Neuropsychopharmacology. Nashville, Tenn, ACNP, 2000.

9. Smith RC, Lindenmayer J-P, Khandat A, Wahab M, Bodala P,Rosenberger J. A prospective study of glucose and lipid metabolism with atypical and conventional antipsychotics (Poster), in Proceedings of the 14th Annual Research Conference of the New York State Office of Mental Health. Albany, New York State Office of Mental Health, 2001

10. World Health Organization .The ICD-10 Classification of Mental and Behavioural Disorders. Geneva, 1992. Available from URL; http://www.mentalhealth.com/icd/p22-ps01

11. Lindenmayer JP, Czobor P, Volavka J, Citrome L, Sheitman B, McEvoy JP et al. Changes in glucose and cholesterol levels in patients with schizophrenia treated with typical or atypical antipsychotics. Am J Psychiatry. 2003;160:290-6.

12. Lambert BL, Chou CH, Chang KY, Tafesse E, Carson W.Antipsychotic exposure and type 2 diabetes among patients with schizophrenia: a matched case-control study of California Medicaid claims. Pharmacoepidemiol Drug Saf. 2005 Jun; 14(6):417-25.

13. Fuller MA, Shermock KM, Secic M, Grogg AL. Comparative study of the development of diabetes mellitus in patients taking risperidone and olanzapine. Pharmacotherapy. 2003 Aug; 23(8):1037-43.

14. Henderson DC, Cagliero E, Copeland PM, Borba CP, Evins E, Hayden D, Weber MT, Anderson EJ, Allison DB, Daley TB, Schoenfeld D, Goff DC. Glucose metabolism in patients with schizophrenia treated with atypical antipsychotic agents: a frequently sampled intravenous glucose tolerance test and minimal model analysis. Arch Gen Psychiatry. 2005 Jan; 62(1):19-28.

15. Winkel VR, De Hert M, Wampers M, Van Eyck D, Hanssens L, Scheen A, Peuskens J. Major changes in glucose metabolism, including new-onset diabetes, within 3 months after initiation of or switch to atypical antipsychotic medication in patients with schizophrenia and schizoaffective disorder. J Clin Psychiatry. 2008 Mar; 69(3):472-9.

16. Melkersson KI, Hulting AL, Brismar KE.Different influences of classical antipsychotics and clozapine on glucose-insulin homeostasis in patients with schizophrenia or related psychoses. J Clin Psychiatry. 1999 Nov; 60(11):783-91.

17. Wirshing DA, Boyd JA, Meng LR, Ballon JS, Marder SR, Wirshing WC.The effects of novel antipsychotics on glucose and lipid levels. J Clin Psychiatry. 2002 Oct; 63(10):856-65.

18. Wirshing DA, Wirshing WC, Kysar L, Berisford MA, Goldstein D, Pasdag J, Mintz J, Marder SR. Novel antipsychotics: comparison of weight gain liabilities. J Clin Psychiatry.1999; 100:3 -16.

19. Herran A,Garcia-Unzueta M.T, Amado JA et al. Effects of long-term treatment with antipsychotics on serum leptin levels. British Journal of Psychiatry.2001; 179, 5962.45.

20. Melkersson KI, Hultin A-L, Brismar KE. Different influences of classical antipsychotics and clozapine on glucose-insulin 141 homeostasis in patients with schizophrenia or related psychoses. J Clin Psychiatry. 1999;60:783-791,

21. Foss MC, Paula FJ, Paccola GM, Piccinato CE. Peripheral glucose metabolism in human hyperprolactinaemia. Clin Endocrinol (Oxf). 1995 Dec; 43(6):721-6.

22. Schernthaner G, Prager R, Punzengruber C, Luger A. Severe hyperprolactinaemia is associated with decreased insulin binding in vitro and insulin resistance in vivo. Diabetologia. 1985 Mar; 28(3):138-42.

23. Johnson DE, Yamazaki H, Ward KM, Schmidt AW, Lebel WS, Treadway JL, Gibbs EM, Zawalich WS, Rollema H. Inhibitory effects of antipsychotics on carbachol enhanced insulin secretion from perused rat islets: role of muscarinic antagonism in antipsychoticinduced diabetes and hyperglycaemia. Diabetes care.2005;54:1552-1558

24. American Diabetes Association. Consensus development conference on antipsychotic drugs and obesity and diabetes. Diabetes Care 2004; 27:596-601.

25. Ebenbichler CF, Laimer M, Eder U, Mangweth B, Weiss $\mathrm{E}$, Hofer A, and others. Olanzapine induces insulin resistance: results from a prospective study. J Clin Psychiatry 2003; 64:1436-9.

26. Houseknecht $\mathrm{K}$ et al. Diabetogenic effects of some atypical antipsychotics: Rapid, whole body insulin resistance following a single dose. Diabetologia. 2005;48(Suppl 1):A212.

27. Newcomer JW, Haupt DW, Fucetola R, Melson AK, Schweiger JA, Cooper BP, Selke G. Abnormalities in glucose regulation during antipsychotic treatment of schizophrenia. Arch Gen Psychiatry. 2002 Apr; 59(4):337-45. 